\title{
COMUNICAÇÃO E CULTURA
}

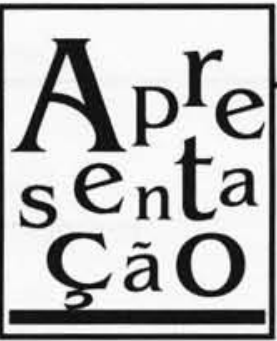

Quando nascemos, encontramos uma história em processo. É como se estivéssemos tomando um trem que está vindo de muitas e muitas outras estações. Ele carregou milhões de pessoas que já realizaram, juntas, um número incontável de ações. Elas construíram um jeito de ser, de viver, de "entender" o tempo e a realidade cotidiana. Entramos nesse trem, banhamo-nos nessa cultura.

As ações realizadas se manifestaram numa pluralidade de significações registradas pelas palavras nos discursos. São essas as palavras que usamos para nos comunicar. São elas que nos entregam "descrito" e "interpretado" pelas gerações anteriores o pequeno espaço do mundo que temos para viver. Já na década de 20, Lippmann escrevia: "Cada um de nós vive e trabalha numa pequena parte da superfície da Terra, move-se num círculo restrito e, das coisas que conhece, conhece intimamente apenas umas poucas. De qualquer acontecimento público que exerça amplos efeitos, na melhor das hipóteses, só vemos uma fase e um aspecto"1.

Em 1977, Ecléa Bosi publica "A opinião e o estereótipo", na Revista Contexto. Diz a autora: "O nosso círculo de experiência é limitado. O nosso espaço vivido no mundo é pequeno. Embora tenhamos a ilusão de participar intensamente desse mundo único que encerra os seres viventes, conhecemos, na verdade, um reduzido espaço dentro dele, e um caminho familiar pelo qual nos guiamos e onde repetimos nossos passos, entre a infinidade de caminhos oferecida a outros seres. (....) Conhecemos algumas pessoas, algumas coisas, alguns pedaços de paisagens, de ruas, alguns livros. Presenciamos alguns fatos, mas não presenciamos a maior parte dos fatos sobre os quais conversamos. Confia-mos, porém, nas pessoas que viveram e presenciaram esses fatos, e o pensamento e o discurso quotidiano se alimentam dessa confiança social" 2 .

\section{A AUTORA \\ Maria Aparecida Baccega \\ Doutora em Letras e Ciências da Comunicação. Professora Associada da Escola de Comunicações e Artes da USP. Especialista em Linguagem Verbal nos Meios de Comunicação. Coordenadora do Curso "Gestão de Processos Comunicacionais".}

1. LIPPMANN, Walter. Estereótipos. In: STEINBERG, Ch (org). Meios de comunicação de massa. São Paulo: Cultrix, 1970. p. 149.

2. BOSI, Ecléa. A opinião e o estereótipo. Contexto (2): 97-104. São Paulo: Hucitec, março de 1977. (o grifo é nosso) 
E são essas pessoas, nas quais confiamos, que vão nos contar os acontecimentos, que vão nos comunicar os "fatos" que não vimos.

\section{II}

Mas o que é comunicar?

Comunicar é contar a alguém alguma coisa. É ouvir de alguém alguma coisa. Pressupõe, portanto, o diálogo. Nós só falamos, só contamos alguma coisa quando temos algum interesse em contar e/ou supomos haver interesse (ou queremos "criar" esse interesse) da parte de quem ouve. Também é o interesse que nos dispõe a ficar ouvindo o que o outro tem a dizer. Logo, a comunicação procede de alguém (há alguém que fala), dirige-se para alguém (o outro) e procura persuadir, convencer (em maior ou menor grau).

Para que haja entendimento entre as partes, para que haja comunicação, é preciso que a linguagem seja "comum", ou seja, que os indivíduos que participam desse diálogo sejam indivíduos socialmente organizados, que fizeram um "contrato" entre eles e instituíram os significados. São essas significações que encontramos prontas, que chegaram até nós nos discursos carregados pelo trem. Este trem (a História), no qual embarcamos ao nascer, carrega, portanto, discursos que portam significações que nos são "impostas". Logo, a mediação entre o homem e a realidade objetiva é exercida pelas linguagens, sobretudo pela linguagem verbal, pela palavra. É ela que porta, que carrega a "descrição" e a "interpretação" da realidade.

Essa "descrição" e "interpretação" referem-se não apenas à categorização de objetos materiais como também a valores. Assim: em São Paulo, designamos um dos cursos de água que cortam a cidade de rio Tietê. Esse tipo de curso d'água, no Pará, será chamado de igarapé (ou seja, caminho d'água, rio pequeno), pois rio para eles é, por exemplo, o Amazonas, que tem um volume d'água muitas e muitas vezes maior. $\mathrm{Na}$ área dos valores, basta lembrarmos as palavras "índio" e "negro".

Como diz Marilena Chauí, "os índios, em fase de extermínio, são considerados irresponsáveis (isto é, incapazes de cidadania), preguiçosos (isto é, mal-adaptáveis ao mercado de trabalho capitalista), perigosos, devendo ser exterminados ou, então, 'civilizados' (isto é, entregues à sanha do mercado de compra e venda da mão-de-obra, mas sem garantias trabalhistas porque 'irresponsáveis') $)^{3}$ ".

Nesses 300 anos da morte de Zumbi, o grande líder de Palmares, ainda encontramos, como lembra Solange M. Couceiro de Lima, a representação social do negro como ignorante, raça inferior e perigoso. Há até um ditado que diz: "Negro parado é suspeito; correndo, é culpado". Diz Couceiro de Lima: "toda a representação negativa que se constrói na sociedade brasi-

3. CHAỨ, Marilena. Conformismo e resistência. 4 ed. São Paulo: Brasiliense, 1989. p. 56. 
leira sobre o negro e que circula por ela, é captada, reelaborada e devolvida pela mídia com grande eficiência" 4 .

Logo, a famosa democracia racial do Brasil configura-se, ainda, como objetivo a ser alcançado. E, de preferência, rapidamente.

\section{III}

A comunicação é, portanto, da própria natureza do ser humano. O desenvolvimento da tecnologia possibilitou o surgimento de suportes que fazem com que "o que é dito" e/ou "mostrado" pelo outro chegue imediatamente aos nossos ouvidos, aos nossos olhos.

Tudo isso se traduz numa outra realidade para a comunicação. Para nos aproximarmos criticamente dessa nova realidade, muitos são os tópicos para reflexão. Entre eles, Comunicação \& Educação 5 elegeu alguns: há distinção entre comunicação e mídia?; como (e quem) desenha o mundo que chega ao nosso conhecimento, contando-nos o que ocorre?; quem pauta os assuntos da agenda que discutimos no nosso cotidiano? Esses, entre outros, são temas dos artigos que compõem este número.

\section{ARTIGOS NACIONAIS}

José Nêumanne, em Entre a trincheira de combate e a caixa registradora, traça uma distinção entre comunicação e mídia. Para ele, a "fraternidade de combate", conforme Albert Camus denominou a imprensa, praticamente não existe mais. Em seu lugar, surge "a grande indústria que produz para a enorme feira livre da curiosidade popular" - a mídia, que se mantém "graças a uma engenhosa mistura de marketing, serviços e notícia".

$\mathrm{Se}$, como afirmamos, a comunicação pressupõe uma cultura onde as significações são verdadeiros "contratos" firmados entre os indivíduos que dela participam, como fica, então, o nosso conhecimento do mundo, quando os acontecimentos nos são narrados por indivíduos de culturas diferentes? Segundo Sônia Virgínia Moreira, em $\mathbf{O}$ mundo pelas agências de notícias, "devido à crise econômica iniciada na década de 80 , inúmeros meios de comunicação - principalmente jornais e emissoras de TV — desmontaram as suas equipes de correspondentes no exterior e passaram a depender em grande parte das notícias distribuídas pelas agências internacionais." Isso evidencia que "os leitores, ouvintes e telespectadores brasileiros enxergam o mundo sob a ótica de um olhar estrangeiro". Depois de apresentar dados referentes a vários meios de comunicação, a autora afirma que os repórteres 
estrangeiros, "por não possuírem referências das diferentes culturas nacionais, certamente estarão transmitindo informações genéricas e padronizadas - bastante distintas daquelas que poderiam estar sendo divulgadas caso tivessem como redatores correspondentes brasileiros sediados em capitais estrangeiras".

Agenda setting e educação, de Clóvis de Barros Filho, vai tratar da construção da agenda temática, problematizando essa questão no campo da educação. Para ele, "trata-se de uma questão de ética. Cabe uma advertência aos alunos. A imposição de um produto codificado e, portanto, em certa medida ficcional, como sendo a realidade, inacessível para o leitor, é a própria essência do produto informativo mediatizado. A ausência aparente do autorjornalista, provocada por uma padronização estilística crescente (manuais de estilo) não significa ausência de codificador, de código, de intermediário e, conseqüentemente, de seleção".

"Todo homem deve ser capaz de viver e agir no espaço do saber e as tecnologias utilizadas pela humanidade sempre tiveram um papel fundamental na organização das sociedades humanas", começa afirmando Luís Lindolfo Nogueira, em Educação a distância. As novas tecnologias em educação não significam inovações com as quais se decoram as escolas: o que importa, realmente, é o uso que se faz delas. Ao tratar desse uso, Luís Lindolfo afirma: "o uso de qualquer mídia educativa deve respeitar as diversidades de aproximação, levando em consideração que os objetos não podem ser estudados independentemente das pessoas". E as pessoas pertencem a um determinado universo cultural que precisa ser respeitado. Só assim se garantirá o êxito da Educação a Distância.

O artigo Educação ambiental e educação, de Gláucia Davino e André Davino, mostra a importância do ser humano nas questões referentes ao meio ambiente. Para eles, "o meio ambiente não inclui apenas os aspectos naturais da Terra (....), mas igualmente aspectos artificiais e culturais (os chamados bens antrópicos)". Vale a pena refletir sobre as relações entre cultura, meio ambiente e comunicação, como propõe o artigo.

O grande desafio vem pensado por Antônio Albino Canelas Rubim, no artigo Quatro anos de quê? Entendendo-se a comunicação como necessidade a ser recuperada no mundo da mídia, que características deve ter o curso universitário que se propõe a formar o comunicador? "Como pensar e construir, pois não se trata apenas de imaginar, uma outra Universidade e um outro curso de comunicação que, ao reter qualidade, seduza e realize uma formação que satisfaça, recompondo no limite possível a interação entre vida e vida universitária?" Várias e importantes propostas são discutidas pelo autor.

\section{ARTIGO INTERNACIONAL}

Transmissão educativa e desenvolvimento constitui a última das três partes do artigo Transmissão Educativa e trata da Educação para o 
Desenvolvimento. Apontando falhas do processo, diz: "o uso da transmissão para sistemas de extensão era geralmente ineficiente. Os produtores dos programas eram, na maioria das vezes, professores de agronomia ou saúde, vindos de grandes cidades e, literalmente, liam no microfone lições de manuais, nos quais se utilizava uma linguagem técnica, seca e ininteligível para a população rural". Ou seja: sem respeito ao universo cultural do aluno nenhum programa obterá êxito.

\section{ENTREVISTA}

Gianfrancesco Guarnieri é o artista do povo, entrevistado por Roseli Fígaro. Enfeixando o respeito ao outro como poucos praticaram, a leitura de Um artista do povo nos faz refletir sobre os avanços e recuos da história das artes no Brasil, durante as últimas décadas. Para ele, "a individualidade tem que chegar à compreensão de que ela só é, cada vez de uma forma mais integral, no coletivo; se ela inverte isso, faz com que sua individualidade se perca no individualismo, aí é uma cegueira". Vale a pena refletir com Guarnieri e incorporar um pouco de sua lucidez e permanente esperança.

\section{CRÍTICA}

Já que estamos falando tanto em universo cultural próprio, como fica A Voz do Brasil? Quem escreve sobre o tema é Elias Novelino. Quem deve ser o dono d'A Voz do Brasil traz dados importantes para pensar a questão.

José Roberto D'Elboux fala sobre o Festival de Cannes 95. Brasileiro, ele fala com muito respeito, entre outras, da propaganda japonesa: "ela é tão estranhíssima e maluca aos nossos olhos de pobres ocidentais, que acaba se transformando em um verdadeiro cult do festival". É mesmo outro universo cultural.

\section{DEPOIMENTO}

Meu personagem inesquecível é o depoimento emocionado do escritor Izaías Almada. Ele fala sobre seu último livro Florão da América, ao mesmo tempo em que vai mostrando "a mesmice e a unanimidade boçal" dos meios de comunicação.

O rádio, sempre tão presente na vida de todos, volta no depoimento de Cristina Braga. Nas ondas do rádio mostra o desprestígio que o veículo tem entre os recém-formados em comunicação e as muitas alegrias que só ele é capaz de dar ao profissional. 


\section{EXPERIÊNCIA}

Vale a pena conhecer (e praticar, se possível) a atividade contida em Arte, Português, História: trabalho interdisciplinar com quintas séries. Clara Rosa da Costa, Sílvia Letícia de Andrade e Marisa de Jesus Penhalber, juntas, produziram, com os alunos, os livros que contam a história das famílias deles. $\mathrm{O}$ trabalho possibilita não só conhecimento da realidade histórica como concretização da noção de espaço-tempo. Mais que isso: amplia o respeito ao universo cultural do próprio aluno e do outro.

\section{POESIA}

A revista tem seção nova. O Conselho Editorial decidiu que o prazer da poesia, indispensável, não poderia faltar. E para começar ninguém melhor que Renata Pallottini, grande poeta (como ela prefere ser chamada), que também é dramaturga. Vamos fruir Quixote e seu cavalo.

\section{SERVIÇOS}

Neste número trazemos orientações sobre como usar o Museu de Geociências da USP. Quem informa é Maria Lúcia Rocha Campos.

Televisão e Criança, de Beth Carmona et al traz os resultados do Seminário "Televisão e Infância", realizado pela TV Cultura e Instituto Goethe. Neste Relatório os autores apresentam, inclusive, uma série de sugestões sobre o tema.

\section{BOLETIM BIBLIOGRÁFICO}

A Videografia, a Bibliografia especializada sobre a telenovela brasileira e a Bibliografia na área de Comunicação e Educação continuam. Esperamos que essa seção esteja sendo útil também para você. 